\title{
Labyrinthe
}

40 | 2013

Comme les abeilles

\section{L'abeille et la ruche comme métaphores politiques chez Maeterlinck}

Lætitia Mouze

\section{(2) OpenEdition}

1 Journals

Édition électronique

URL : http://journals.openedition.org/labyrinthe/4328

DOI : $10.4000 /$ labyrinthe.4328

ISSN : 1950-6031

Éditeur

Hermann

Édition imprimée

Date de publication : 1 mars 2013

Pagination : 121-123

ISBN : 9782705688400

\section{Référence électronique}

Lætitia Mouze, «L'abeille et la ruche comme métaphores politiques chez Maeterlinck », Labyrinthe [En ligne], 40 | 2013, mis en ligne le 01 mars 2015, consulté le 22 avril 2019. URL : http:// journals.openedition.org/labyrinthe/4328; DOI : 10.4000/labyrinthe.4328

Propriété intellectuelle 


\title{
L'abeille et la ruche comme métaphores politiques chez Maeterlinck
}

\author{
Lætitia Mouze
}

L'intelligence des abeilles est une préoccupation constante de Maeterlinck. Cette intelligence, il cherche à la défendre tout au long de l'ouvrage, jusqu'à y consacrer la dernière partie, « le progrès de l'espèce », où il cherche à montrer que les abeilles sont intelligentes, et que cette intelligence a progressé. Il fait une remarque qui paraît pertinente, en adéquation apparente avec des théories récentes de la réflexion sur les animaux, lorsqu'il récuse la pertinence de la notion d'instinct. Il s'explique de l'importance qu'il donne à cette question de savoir si les abeilles sont intelligentes ou non, et cela avec deux arguments: si elles le sont, cela nous éviterait de nous sentir seuls dans l'univers - c'est une raison existentielle. Et puis une deuxième raison, essentielle: il s'agirait pour l'homme de cesser de croire qu'il est le roi de la création:

[...] que nous importe que les abeilles soient plus ou moins intelligentes ? [...] Sans rien exagérer, je crois que l'intérêt que nous y avons est des plus appréciables. À trouver, hors de nous une marque réelle d'intelligence, nous éprouvons un peu de l'émotion de Robinson découvrant l'empreinte d'un pied humain sur la grève de son île. [...] Si nous étions seuls à posséder et à maintenir une parcelle de matière en cet état particulier de floraison ou d'incandescence que nous nommons l'intelligence, nous aurions quelque droit de nous croire privilégiés, de nous imaginer que la nature atteint en nous une sorte de but [...].

Il ne faut pas croire que Maeterlinck s'emporte ici, qu'il s'exalte, et en dise plus qu'il ne le pense réellement. Cette humanisation des abeilles est parfaitement consciente, revendiquée et assumée: c'est une position de l'ouvrage. Elle a, en toute rigueur, deux conséquences : la première est politique - c'est-à-dire qu'on trouve dans l'ouvrage, à plusieurs reprises, des propos politiques liés aux considérations sur l'abeille, qui sont aussi 


\section{Labyrinthe, $n^{\circ} 40$}

des propos politiques concernant l'humanité. Dans le livre II, Maeterlinck note ceci :

Tout indique que ce n'est pas la reine, mais l'esprit de la ruche qui décide l'essaimage. Il en est de cette reine comme des chefs parmi les hommes; ils ont l'air de commander, mais eux-mêmes obéissent à des ordres plus impérieux et plus inexplicables que ceux qu'ils donnent à qui leur est soumis.

Deux autres passages présentent plus d'intérêt: toujours dans le livre II, au chapitre 9 , dans un contexte où Maeterlinck répond à ceux qui prennent appui sur la façon dont l'essaimage se passe, sur certaines circonstances de l'essaimage, pour dénier aux abeilles toute intelligence ; à ces gens-là, Maeterlinck répond en prenant comme argument un habitant de Mars ou Vénus qui nous verrait de loin aller et venir dans nos villes.

[...] il aurait bien du mal à découvrir dans « nos petits points noirs » la grande direction morale, l'admirable sentiment unanime qui éclate dans la ruche, «Où vont-ils ? se demanderait-il, après nous avoir observés durant des années ou des siècles; que font-ils ? quel est le lieu central et le but de leur vie ? obéissent-ils à quelque dieu ? Je ne vois rien qui conduise leurs pas. Un jour ils semblent édifier et amasser de petites choses, et le lendemain les détruisent et les éparpillent. Ils s'en vont et reviennent, ils s'assemblent et se dispersent, mais on ne sait ce qu'ils désirent. Ils offrent une foule de spectacles inexplicables. On en voit, par exemple, qui ne font pour ainsi dire aucun mouvement.

Maeterlinck glisse alors vers la satire politique:

On les reconnaît à leur pelage plus lustré; souvent aussi ils sont plus volumineux que les autres. Ils occupent des demeures dix ou vingt fois plus vastes, plus ingénieusement ordonnées et plus riches que les demeures ordinaires. Ils y font tous les jours des repas qui se prolongent durant des heures et parfois fort avant dans la nuit. Tous ceux qui les approchent paraissent les honorer, et des porteurs de vivres sortent des maisons voisines et viennent même du fond de la campagne pour leur faire des présents. Il faut croire qu'ils sont indispensables et rendent à l'espèce des services essentiels, bien que nos moyens d'investigation 
L'abeille et la ruche comme métaphores politiques chez Maeterlinck

ne nous aient point encore permis de reconnaître avec exactitude la nature de ces services. On en voit d'autres, au contraire, qui dans de grandes cases encombrées de roues qui tourbillonnent, dans des réduits obscurs, autour des ports et sur de petits carrés de terre qu'ils fouillent de l'aurore au coucher du soleil, ne cessent de s'agiter péniblement. Tout nous fait supposer que cette agitation est punissable. On les loge, en effet, dans d'étroites huttes, malpropres et délabrées. Ils sont couverts d'une substance incolore. Telle paraît être leur ardeur à leur œuvre nuisible, ou tout au moins inutile, qu'ils prennent à peine le temps de dormir et de manger. Leur nombre est aux premiers comme mille est à un. Il est remarquable que l'espèce ait pu se maintenir jusqu'à nos jours dans des conditions aussi défavorables à son développement. Du reste, il convient d'ajouter que, hormis cette obstination caractéristique à leurs agitations pénibles, ils ont l'air inoffensif et docile et s'accommodent des restes de ceux qui sont évidemment les gardiens et peut-être les sauveurs de la race.

L'ironie du passage est patente: on passe insensiblement du propos « anthropomorphique » sur les abeilles à un renversement de l'accusation d'anthropomorphisme et à la satire politique, voire à la charge politique. On retrouve un passage du même acabit dans le livre VII, au chapitre 16. L'anthropomorphisme de Maeterlinck le conduit à des propos politiques. 